\title{
Visual Shape Recognition in Crayfish as Revealed by Habituation
}

\author{
Cinzia Chiandetti* and Andrea Caputi
}

University of Trieste, Italy

*Corresponding authors (Email: cchiandetti@units.it)

Citation - Chiandetti, C., \& Caputi, A. (2017). Visual shape recognition in crayfish as revealed by habituation. Animal Behavior and Cognition, 4(3), 242-251. https://doi.org/10.26451/abc.04.03.04.2017

\begin{abstract}
To cope with the everyday challenges that they encounter in their evolutionary niche, crayfish are considered to rely mainly on chemical information or, alternatively, on tactile information, but not much on vision. Hence, research has focused on chemical communication, whereas crayfish visual abilities remain poorly understood and investigated. To fill in this gap, we tested whether crayfish (Procambarus clarkii) can distinguish between two different visual shapes matched in terms of luminance. To this aim, we measured both the habituation response to a repeated presentation of a given shape, a downright $\mathrm{Y}$, and the response recovery when a novel shape was presented. The novel shape could be either a Möbius or the same Y-shape but upright rotated. Our results demonstrate that, after habituation to the downright $\mathrm{Y}$, crayfish showed a significantly higher response recovery to the Möbius as compared to the upright rotated Y. Hence, besides relying on chemo-haptic information, we found that crayfish can use sight alone to discriminate between different abstract geometrical shapes when macroscopically different. Failure to discriminate between the downright $\mathrm{Y}$ and its inversion or a generalization from the presence of a shape with three points creating a simple category, are both likely parsimonious explanations that should be investigated systematically in further studies. A future challenge will be understanding whether crayfish are capable of generalized shape recognition.
\end{abstract}

Keywords - Visual discrimination, Object rotation, Habituation, Recovery response, Crayfish

Decapod crustaceans, which are a heterogeneous class of primarily aquatic organisms, make extensive use of olfaction. The importance of chemical communication, which is now well-understood (Ache \& Derby, 1985; Breithaupt, 2011), is attested by at least two empirical facts. The first is that chemical signals are vital in a wide range of situations: from feeding to territorial behaviors and defense from predators, urine-borne products and pheromones are used by crustaceans also in sex identification for mating and recognition of dominance status (lobsters: Breithaupt \& Atema, 1993; crabs: Bamber \& Naylor, 1997; crayfish: Hazlett, 1985; shrimps: Caskey \& Bauer, 2005). The second concerns adult neurogenesis, a characteristic feature of the central olfactory pathways of these species, which testifies to the pivotal role of olfaction during the whole crustaceans' lifespan (reviewed in Schmidt, 2007).

The pairs of short antennules and the two long antennae do support, with different kind of receptors, the encoding of both chemical and thigmotactic information (Sandeman, 1985, 1989). A partial separate involvement of the two different appendages for olfaction and touch has been proposed, with chemoreception based mainly on the antennules and tactile perception being a prerogative of the pair of antennae. Because the long flagella can be moved widely within the three dimensions, they are important for several behaviors. Flagella serve to monitor mechanically the object position, gather information about its direction whenever the stimulated sensilla change over time (Sandeman \& Varju, 1988; Zeil, 
Sandeman, \& Sandeman, 1985), locate the prey independently of the possibility to rely on vision (Breithaupt, Schmitz, \& Tautz, 1995; Zeil et al., 1985), and navigate (Basil \& Sandeman, 2000). When information can be collected by one antenna only, the crayfish Cherax destructor make use of the residual intact one to explore the environment (McMahon, Patullo, \& Macmillan, 2005), but no compensatory information is obtained via other appendages like, for instance, the claws (Koch, Patullo, \& Macmillan, 2006). Because in natural conditions antennal loss is an extremely common injury, crayfish would highly benefit from cross-modal redundancy, which has indeed been shown at least for compensatory postural changes following selective haptic deprivation through antennal ablation. Such counterweighted behaviors appear also after visual deprivation during locomotion (Smith \& Dunham, 1990).

Logically, how much an animal depends on a specific sensory channel correlates with the circumstances under which it ordinarily moves about, orients and fights. In the crayfish Austropotamobius pallipes, specific selective pressures (as a brief mating period and low population density) may be responsible for the integrated use of chemical and visual signals as documented for sex recognition (Acquistapace, Aquiloni, Hazlett, \& Gherardi, 2002).

Crayfish occupy heterogeneous environments ranging from murky channels and ponds to clear streams, environments providing obvious differences in terms of available light. To establish the sensory hierarchy used by the rusty crayfish Orconectes rusticus during agonistic interactions, Callaghan, Weisbord, Dew, and Pyle (2012) proceeded via a systematic impairment of olfaction, touch, and vision. This is the most complete investigation available in the literature and it shows that the dominance status is signaled mainly through olfaction, whereas touch and vision supply only complementary information. In a consistent fashion, the antennule ablation affects animal's ability to identify the other's sex (Cowan, 1991). The same ability is not compromised if the animal is blindfolded (Bushmann, 1999). However, a crucial factor determining which sense may prevail is the environmental illumination, because the less light is available, the less visually-mediated behaviors are shown, and compensation is possible via tactile information (Bruski \& Dunham, 1987).

A fascinating question is whether crayfish can rely on vision for their interaction with the environment. In semi-natural conditions, different species of crustaceans have proved capable of visual recognition of opponents through learning of specific facial features (for a review, see Gherardi, Aquiloni, \& Tricarico, 2012; American lobster: Gherardi, Cenni, Parisi, \& Aquiloni, 2010; Karavanich \& Atema, 1998; crayfish: Van der Velden, Zheng, Patullo, \& Macmillan, 2008; crab: Cannicci, Morino, \& Vannini, 2002). Such sensitivity to visual cues in social contexts intriguingly parallels that of insects (AvarguèsWeber, Deisig, \& Giurfa, 2015). Indeed, a Pancrustacean common ancestor (Regier, Shultz, \& Kambic, 2005) directly links insects and decapods, which share a compound eye and a strikingly similar neural organization of the visual system (Homberg, 2008). Given this comparable physical constraint, it would not be surprising to find functional similarities among insects and crustaceans, an issue that might be worth investigating systematically.

To tackle this question, here we will focus on a specific species of crayfish, the Procambarus clarkii, retained to be mainly a nocturnal animal (Page \& Larimer, 1972). As discussed previously, also this fresh water red swamp crayfish uses primarily chemoreception to determine the dominance status of opponents (Zulandt-Schneider, Schneider, \& Moore, 1999). The disputes to form social hierarchies depend critically on pairwise interactions, which are spontaneously exhibited already by juveniles. Under laboratory controlled conditions, it has been demonstrated that juveniles lacking any social interaction show fights and displays that resemble in all aspects those of the adults (Issa, Adamson, \& Edwards, 1999). Furthermore, both adults and juveniles orient the antennae toward a stimulus such as a jet of water or a vibration that, in ecological hydrodynamic, resemble a moving prey (Schmitz, 1992). However, this species is particularly active also during daylight and can colonize new territories by walking in the countryside outside the aquatic environment (Gherardi, Barbaresi, \& Salvi, 2000). It is therefore conceivable that these animals could highly profit from sophisticated forms of visual processing as has been documented in different species of wasps (Sheehan \& Tibbetts, 2011; Tibbetts, 2002). Aquiloni, Buřič, and Gherardi (2008) showed that females of $P$. clarkii chose the dominant male to mate with after watching male-male competitions, probably by extracting the information about the winner from 
eavesdropping the result of the fights, which seems a quite elaborated visual ability. The compound eye of crayfish is sensitive to different colors (Nosaki, 1969), to polarized light (Muller, 1973), and to visual cues coming from reflective surfaces. By scoring the reaction of crayfish in front of a mirror, it appeared that previous experience modulates crayfish behavior. Animals reared in isolation preferentially avoid the reflection, whereas those reared in pairs increase the time spent to make displays in front of it (Drozdz, Viscek, Brudzynski, \& Mercier, 2006). Furthermore, P. clarkii show a compensatory eye-rotation response as a function of external factors as the light source and the orientation of a solid substrate (Fay, 1973). On this background, it becomes evident that vision may offer a significant source of information for crayfish, yet it remains to be understood whether they are capable of mastering visual discrimination tasks.

One study addressed this issue in the fiddler crab (Uca pugilator). The crabs were observed in a two-alternative forced choice paradigm and showed spontaneous preference for certain shapes matched for size (Langdon \& Herrnkind, 1985). Because the fiddler crabs are known for using a waving claw as a conspicuous mating visual signal (How, Zeil, \& Hemmi, 2009) and can use the visual horizon to categorize dangerous from otherwise innocuous stimuli (Layne, Land, \& Zeil, 1997), it is perhaps not surprising that they can perform visual discrimination between shapes that are uncommon for the speciesspecific biotype (i.e., triangles, circles, etc.). However, to the best of our knowledge, this is the only study that has used abstract geometrical shapes to examine visual abilities in crustaceans, whereas no comparable investigation is available for the crayfish $P$. clarkii, a limitation that makes any cross-species generalization unwarranted.

Hence, the present work is twofold: on the one side, we aimed at studying whether crayfish can use visual information in a simplified and controlled situation in which other chemical and tactile information is absent; on the other side, we assessed whether crayfish can discriminate abstract geometrical visual shapes. Briefly, we presented 50 individuals with a downright $\mathrm{Y}$-shape and, after they habituated to it, half of the animals was tested for the response recovery with a novel shape (a Möbius), while the remaining were tested with the same Y-shape but this time $180^{\circ}$ tilted. On the assumption that crayfish are able to perform mental rotation, we expected their response recovery to be higher to the novel stimulus as compared to the same habituated stimulus when presented $180^{\circ}$ rotated.

\section{Method}

\section{Subjects}

Place of collection. The population of 50 Procambarus clarkii (28 females) belongs to the artificial channel area called "Bonifica del Brancolo" (4546' N, 1330' E, GO, Italy), in between the channel Brancolo and the Adriatic Sea. Individuals were collected twice between April and July 2016 and left to acquaint with the captive environment for at least 10 days before the experiments started. Only intact animals measuring from 9.06 to $11.05 \mathrm{~cm}$ (rostrum to telson, mean length \pm S.E.M.: $9.94 \pm 0.09$ ) were randomly distributed in the two testing conditions described below.

Rearing conditions. Each crayfish was reared in a separate rectangular plastic compartment (10 x 14 x $12 \mathrm{~cm})$ punctured on every side and placed within a larger tank $(120 \times 40 \times 40 \mathrm{~cm})$ filled with $90 \mathrm{~L}$ of clean water. Each tank was equipped with filters and pumps to keep the water clean and flowing. The water was changed weekly and the filters were cleaned with the same frequency. The compartments were isolated with opaque partitions in order to minimize the stimulation coming from the outer environment and to prevent animals to see each other. This procedure was deliberately chosen to maximize the reactivity at test. Crayfish were fed ad libitum with pellet SERA Shrimps Natural. The tanks were located in a room with a $12: 12$ dark:light cycle and constant temperature at $21^{\circ} \mathrm{C}$. 


\section{Materials}

Apparatus. The experimental set-up was equipped with a computer and a flat LCD screen on which the animated 3D stimuli were administered (Figure 1a). The screen was placed outside the shorter wall of a rectangular glass tank, which was empty in order to maximize crayfish use of vision. All around the apparatus, a black curtain prevented areas with different illumination (provided only by the frontal white screen) and interference by the experimenter moving in the outer environment. Inside the tank, a transparent plastic cylinder $(12 \mathrm{~cm}$ in diameter) was positioned at $13 \mathrm{~cm}$ from the screen and equally distant from the sidewalls. This cylinder served as a place where the animal could familiarize with the environment before the presentation of the stimuli and, during the administration of the stimuli, with a fixed and comparable starting position. Inside the cylinder, indeed, two white plastic walls restrained the crayfish body in a frontal position with respect to the computer screen. A thin wire, administered from outside the curtain, served to lift the cylinder up and release the crayfish. The behavior was videorecorded from above at a speed of 29 fps.

Stimuli. The 3D animation software Blender has been used to model and animate the three experimental stimuli of red color. The first stimulus is a "Y" $180^{\circ}$ tilted shape, with sharp extremities and the vertical upper arm shorter than the two lateral arms ( $Y$ downright; Figure 1b). The second stimulus is a Möbius (Figure 1c). The third stimulus is the same "Y" shape but this time upright (Y upright; Figure 1d). The Möbius and the "Y" shape had a surface of 44036 and 46050 pixels, respectively. When presented, all stimuli changed in size, increasing from the beginning of the presentation $(1 \mathrm{~cm})$ to its end $(22 \mathrm{~cm})$, thus creating the illusion of an approaching object (looming stimuli). This method is documented to elicit a defensive response both in P. clarkii (Glantz, 1974) and other crustaceans (Oliva, Medan, \& Tomsic, 2007). The total duration of the animation was $3 \mathrm{~s}$ for all stimuli and the stimuli enlargement speed on the screen was $12.7 \%$, as this speed is effective in provoking an alert response in individuals of P. Clarkii (Glantz, ibidem).

a

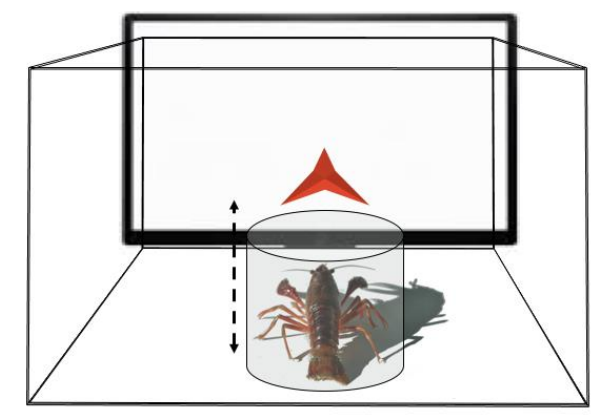

C
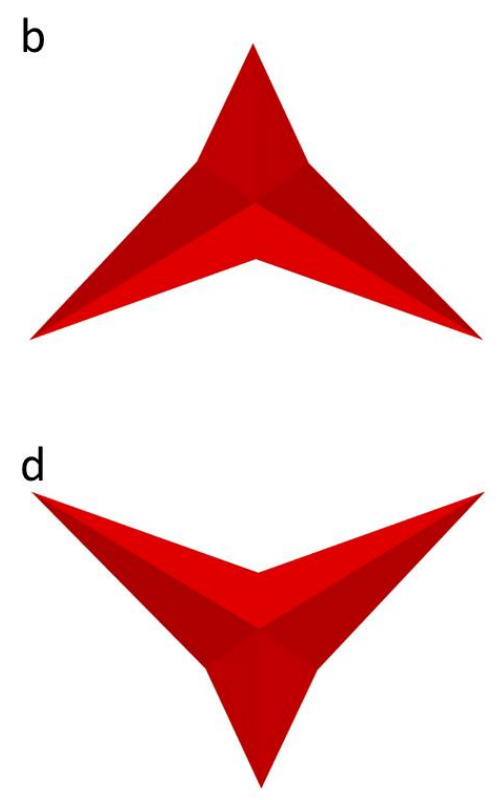

Figure 1. The apparatus and the stimuli. (a) Schematic layout of the apparatus used. (b) After lifting the cylinder up (dashed arrow), the crayfish was presented with the $180^{\circ}$ tilted "Y" shaped stimulus used for the habituation. Then, it was free to move within the apparatus and after 2 min confined again under the cylinder for the next trial. (c) At the $10^{\text {th }}$ trial, either the Möbius or (d) the upright "Y" shaped stimulus was presented for scoring the response recovery. Note that the stimulus in front of the crayfish is shown here for representative purpose only; it was never administered to the crayfish while the cylinder was still lowered. No shadows were created within the apparatus, which was illuminated symmetrically only by the white background of the computer screen. 


\section{Procedure}

The day of testing, one crayfish at a time was left familiarizing under the transparent plastic cylinder placed in the rectangular tank for $10 \mathrm{~min}$ before starting with the stimuli presentation (Figure 1). Then, the cylinder was lifted up, the $3 \mathrm{~s}$ of stimulus presentation administered, and the crayfish was given two minutes to respond before being confined again under the cylinder for the next trial that occurred two minutes later. This procedure was repeated nine consecutive times with one stimulus (habituation) and one further time with a novel stimulus (recovery of the response).

The dependent measure was the intensity of alert response, i.e., the number of frames per second to generate a certain posture. In the operational definition of alert response, we included all movements needed to lift the carapax up and to widely open the chelae. The more intense was the response, the more time was needed to display such posture. All responses were scored offline. A subset of $10 \%$ of the videos was analyzed by a further independent observer, blind to the sequence of stimuli administered. The interrater reliability was ascertained via a Cohen's kappa test, showing a high agreement between the two observers $\kappa=0.928,95 \%$ CI [0.867, 0.989], $p<0.001$.

\section{Results}

The original sample of 50 crayfish was habituated with the Y down shape and then divided in two groups of 25 randomly assigned animals each. Each group of 25 animals was tested for response recovery with either a Möbius or a Y up. Five animals in total did not move during the habituation trials and were excluded from further analyses that were run on 24 animals for the Y up and 21 for the Möbius condition.

The responses at each of the nine habituation trials were entered in a one-way repeated measures ANOVA. Mauchly's test revealed a violation of the assumption of sphericity, $\chi^{2}(35)=454.680$,

$p<0.001$, therefore, the degrees of freedom were corrected using Greenhouse-Geisser estimates of sphericity, $\varepsilon=0.179$. Both groups showed habituation from the first to the ninth trial, $F(1.427,61.356)=$ 7.669, $p=0.003, \eta^{2}=0.151$, with no differences between the two groups of randomly assigned individuals, $F(1,43)=1.102, p=0.300, \eta^{2}=0.025$.

Response recovery was evaluated by comparing the animals' response at trial 10 with that at trial 9. When the response recovery was tested with the Möbius, a significant difference was found, $t(23)=$ $-3.942, p=0.001$, Cohen's $d=-0.547$, paired-sample t-test. By contrast, response recovery measured with the Y up was not significant, $t(20)=-0.954, p=0.352$, paired-sample t-test, as visible in Figure 2.

\section{Discussion}

Our investigation was prompted by noticing that there is a meagre literature concerning $P$. clarkii's abilities to visually discriminate geometrical shapes. By measuring habituation and spontaneous recovery, we found a suitable protocol to start a systematic study of crayfish visual skills, a finding that alone may be worth reporting.

In this preliminary testing situation, we found that all crayfish repeatedly presented with the $\mathrm{Y}$ downright stimulus showed a significant response decrement from the first to the ninth trial. In line with the literature on habituation in crayfish, and crustaceans in general, here we showed habituation in a novel testing condition and for a different response: the looming procedure can be effectively used to produce a reduction in alertness to a repetitive non-noxious stimulus in $P$. clarkii. 


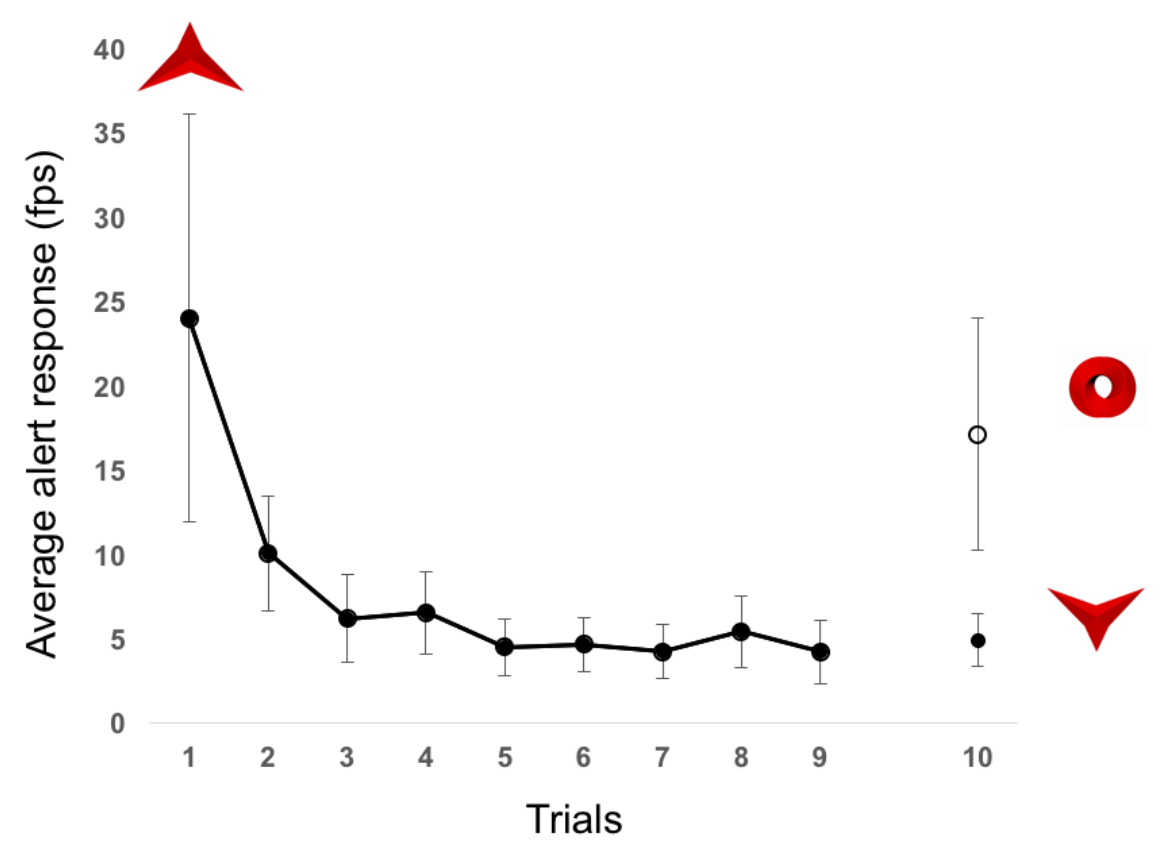

Figure 2. Habituation curve and response recovery. The habituation to the Y downright stimulus (trials 1-9) is shown for the overall group of animals tested with the same procedure (see the main text for the statistics) and it is followed by the response recovery of half of the sample (trial 10) to the Möbius (white circle) and of the other half of the sample to the Y upright (black circle). Bars represent the $95 \%$ confidence intervals.

After habituation occurred, we obtained an intense response recovery when, at the tenth trial, we presented a novel shape, the Möbius, thus confirming that the response decrement observed from trials 1 to 9 was not due to fatigue or sensory adaptation, and that the Möbius appeared as a new and distinct object. Note that despite being very different in terms of global shape, the Y-shape and the Möbius are comparable with respect to the amount of distal stimulation and, therefore, the higher response to the Möbius cannot be accounted for by an overall higher luminance perceived during the Möbius presentation as compared to the $\mathrm{Y}$. In a sense, it may not be surprising that crayfish can discriminate "spiky" from "curvy" shapes. We maximized the difference between the two stimuli used, implementing joint angles and vertexes in the Y-shapes and smooth and circular edges in the Möbius. Most importantly, we observed no response recovery when animals were presented with the same Y-shape but $180^{\circ}$ rotated. It might be tempting to conclude that the two Y-shapes were visually identified as the same object but $180^{\circ}$ rotated and represented as separate from a completely different shape, the Möbius. Indeed, this interpretation would mean that crayfish were able to categorize the two $\mathrm{Y}$ in the same class of elements. However, a more parsimonious explanation can account for the observed results: the possibility exists that the crayfish could not discriminate between the Y-shape and its inverted version. The high dissimilarity between the Y-shape and the Möbius does not apply to the Y-shape and its rotation. At this stage of knowledge, we should consider the failure in discrimination as a more likely explanation than shape categorization, which strongly depends on the ability to distinguish the objects within the same category.

Alternatively, one could make the assumption that the crayfish proved at least able to generalize the presence of three points from the upside-down to the upright Y-shape. If this were the case, however, crayfish should not be easily conditioned to discriminate between two identical but rotated shapes (i.e., to make an example, the upright $\mathrm{Y}$ from the downright $\mathrm{Y}$ ); in insects, for instance, differential conditioning is required for learning complex visual stimuli differences (Giurfa et al., 1999) and, even with differential conditioning, mental rotation appears to operate only within interpolated training sets (Dyer \& Vuong, 2008). Further experiments will help address the issue of whether crayfish can master a categorization task, and which explanation accounts better for the visual performance recorded within the present work. 
Comparative studies have shown that pigeons (Hollard \& Delius, 1982), monkeys (Burmann, Dehnhardt, \& Mauck, 2005), and sea lions (Mauck \& Dehnhardt, 1997) may use a mental rotation strategy and without linear dependence of reaction time upon angle whereas other species rely probably on local features of the rotated stimuli and do not consider the rotation of the whole global shape. However, there are further indications of visual discrimination of rotated objects in fish (Schluessel, Kraniotakes, \& Bleckmann, 2014) and bees on both simple shapes (van Hateren, Srinivasan, \& Wait, 1990; Zhang, Srinivasan, \& Collett, 1995) and complex pictures (Avarguès-Weber, Portelli, Benard, Dyer, \& Giurfa, 2010; Dyer, Neumeyer, \& Chittka, 2005). In consideration of the importance of structure recognition independently of the viewing angle, it seems reasonable to assume that at least some degree of this ability may be found on all the branches of the Darwinian tree. However, we acknowledge that our results are too preliminary to claim that the mental rotation ability can be present in crayfish, too.

Aside from whether crayfish are capable of perceptual generalization, our results add to the accumulating body of studies demonstrating that vision is an essential sensory modality even in aquatic crustaceans with fundamental chemical and haptic abilities. Birds and fish, as well as invertebrate species, despite the lack of a neocortex and the extreme difference in the neural machinery underlying functionally comparable cognitive skills, have shown excellent competencies in many cognitive tasks (reviews in Emery, 2006; Vallortigara, Regolin, Chiandetti, \& Rugani, 2010 for birds; Bshary \& Brown, 2014, for fish; Srinivasan, 2010, for bees; Ikeda, 2009, for octopuses). Alongside these species, crayfish start being numbered among the animals that can integrate cues coming from different sensory modalities, including those from the visual stream. Because they are part of the insect family, with whom they share the compound eye and the organization of the visual system, and because they are mobile even in the terrestrial environment, it is not surprising that crayfish may also resort to the use of vision to respond to environmental and biological challenges such as predation, navigation, discrimination, and learning. On the continuum of visual abilities, the two extremes may be symbolically represented by a basic form of mimicry on one side (by adopting the appropriate color with respect to the background (Bowman, 1942)) and sophisticated eavesdropping for subsequent mate choices on the other side (Aquiloni et al., 2008). Our results add evidence in favor of visual shape discrimination that fits well on such a continuum. The crayfish P. clarkii presents well-documented biological advantages, such as a large number of offspring, resistance to pollution, and tolerance to environmental extremes (all reviewed in Gherardi, 2006). The cognitive abilities preliminarily reported here in the domain of visual discrimination can explain part of the plasticity and adaptivity of this species, in a word its invasiveness.

\section{Acknowledgements}

The experiment complies with the European Community and Italian laws on animal experiments. We thank Massimo Zanetti, Romero Iacuzzo and the Ente Tutela Pesca Friuli Venezia Giulia with its volunteers for helping with crayfish collection. After completion of the experiments, crayfish were not returned to their natural habitat and killed by hypothermia because law forbids the release of invasive species (L.R. 7/2005). This work was partially supported by a UniTs-FRA2015 grant to C.C.

Authors' contribution: Conceptualization: C.C.; Formal analysis and investigation: C.C., A.C.; Original draft preparation: C.C.; Review and editing: C.C., A.C.

Conflicts of Interest: No competing interests declared.

\section{References}

Ache, B. W., \& Derby, C. D. (1985). Functional organization of olfaction in crustaceans. Trends in Neurosciences, 8, 356 - 360. doi:10.1016/0166-2236(85)90122-5

Acquistapace, P., Aquiloni, L., Hazlett, B. A., \& Gherardi, F. (2002). Multimodal communication in crayfish: Sex recognition during mate search by male Austropotamobius pallipes. Canadian Journal of Zoology, 80, 
2041 - 2045. doi:10.1139/z02-171

Aquiloni, L., Buřič, M., \& Gherardi, F. (2008). Crayfish females eavesdrop on fighting males before choosing the dominant mate. Current Biology, 18, 462 - 463. doi:10.1016/j.cub.2008.04.006

Avarguès-Weber, A., Deisig, N., \& Giurfa, M. (2015). Visual cognition in social insects. Annual Review of Entomology, 56, 423 - 443. doi:10.1146/annurev-ento-120709-144855

Avarguès-Weber, A., Portelli, G., Benard, J., Dyer, A., \& Giurfa, M. (2010). Configural processing enables discrimination and categorization of face-like stimuli in honeybees. Journal of Experimental Biology, 213, 593 - 601. doi:10.1242/jeb.039263

Bamber, S. D., \& Naylor, E. (1997). Sites of release of putative sex pheromone and sexual behaviour in female Carcinus maenas (Crustacea: Decapoda). Estuarine, Coastal and Shelf Science, 44, 195 - 202. doi:10.1006/ecss.1996.0211

Basil, J., \& Sandeman, D. (2000). Crayfish (Cherax destructor) use tactile cues to detect and learn topographical changes in their environment. Ethology, 106, 136 - 148. doi:10.1046/j.1439-0310.2000.00524.x

Bowman, T. E. (1942). Morphological color change in the crayfish. The American Naturalist, 76, 332 - 336. doi: $10.1086 / 283473$

Breithaupt, T. (2011). Chemical communication in crustaceans. In T. Breithaupt \& M. Thiel (Eds.), Chemical communication in crayfish (pp. 257-276). New York: Springer -Verlag.

Breithaupt, T., \& Atema, J. (1993). Evidence for the use of urine signals in agonistic interactions of the American lobster. Biological Bulletin, 185, 318. doi:10.1086/BBLv185n2p318

Breithaupt, T., Schmitz, B., \& Tautz, J. (1995). Hydrodynamic orientation of crayfish (Procambarus clarkii) to swimming fish prey. Journal of Comparative Physiology A, 177, 481 - 491. doi:10.1007/BF00187483

Bruski, C. A., \& Dunham, D. W. (1987). The importance of vision in agonistic communication of the crayfish Orconectes rusticus. I: An analysis of bout dynamics. Behaviour, 103, 83 - 107. doi:10.1163/156853987X00288

Bshary, R., \& Brown, C. (2014). Fish cognition. Current Biology, 24, R947 - R950. doi:10.1016/j.cub.2014.08.043

Burmann, B., Dehnhardt, G., \& Mauck, B. (2005). Visual information processing in the lion-tailed macaque (Macaca silenus): Mental rotation or rotational invariance? Brain, Behavior and Evolution, 65, 168 - 176. doi:10.1159/000083626

Bushmann, P. (1999). Concurrent signals and behavioral plasticity in blue crab (Callinectes sapidus Rathbun) courtship. Biological Bulletin, 197, 63 -71. doi: 10.2307/1542997

Callaghan, D. T., Weisbord, C. D., Dew, W. A., \& Pyle, G. G. (2012). The role of various sensory inputs in establishing social hierarchies in crayfish. Behaviour, 149, 1443 - 1458. doi:10.1163/1568539X-00003033

Cannicci, S., Morino, L., \& Vannini, M. (2002). Behavioural evidence for visual recognition of predators by the mangrove climbing crab Sesarma leptosoma. Animal Behaviour, 63, 77 - 83. doi:10.1006/anbe.2001.1882

Caskey, J. L., \& Bauer, R. T. (2005). Behavioral tests for a possible contact sex pheromone in the caridean shrimp Palaemonetes pugio. Journal of Crustacean Biology, 25, 571 - 576. doi: 10.1651/C-2580.1

Cowan, D. (1991). The role of olfaction in courtship behavior of the American lobster Homarus americanus. Biological Bulletin, 181, 402 - 407. doi: 10.2307/1542360

Drozdz, J. K., Viscek, J., Brudzynski, S. M., \& Mercier, A. J. (2006). Behavioral responses of crayfish to a reflective environment. Journal of Crustacean Biology, 26, 463 - 473. doi: 10.1651/S-2687.1

Dyer, A., Neumeyer, C., \& Chittka, L. (2005). Honeybee (Apis mellifera) vision can discriminate between and recognise images of human faces. Journal of Experimental Biology, 208, 4709 - 4714. doi: $10.1242 /$ jeb.01929

Dyer, A. G., \& Vuong, Q. C. (2008). Insect brains use image interpolation mechanisms to recognise rotated objects. PLOS ONE, 3, e4086. doi:10.1371/journal.pone.0004086

Emery, N. J. (2006). Cognitive ornithology: The evolution of avian intelligence. Philosophical Transactions of the Royal Society of London. Series B, Biological Sciences, 361, 23 - 43. doi:10.1098/rstb.2005.1736

Fay, R. R. (1973). Multisensory interaction in control of eye-stalk rotation response in the crayfish (Procambarus clarkii). Journal of Comparative and Physiological Psychology, 84, 527 - 533.

Gherardi, F. (2006). Crayfish invading Europe: The case study of Procambarus clarkii. Marine and Freshwater Behaviour and Physiology, 39, 175 - 191. doi:10.1080/10236240600869702

Gherardi, F., Aquiloni, L., \& Tricarico, E. (2012). Revisiting social recognition systems in invertebrates. Animal Cognition, 15, 745 - 762. doi:10.1007/s10071-012-0513-y

Gherardi, F., Barbaresi, S., \& Salvi, G. (2000). Spatial and temporal patterns in the movement of Procambarus clarkii, an invasive crayfish. Aquatic Sciences, 62, 179-193. doi:10.1007/PL00001330

Gherardi, F., Cenni, F., Parisi, G., \& Aquiloni, L. (2010). Visual recognition of conspecifics in the American lobster, 
Homarus americanus. Animal Behaviour, 80, 713 - 719. doi:10.1016/j.anbehav.2010.07.008

Giurfa, M., Hammer, M., Stach, S., Stollhoff, N., Müller-Deisig, N., \& Mizyrycki, C. (1999). Pattern learning by honeybees: Conditioning procedure and recognition strategy. Animal Behaviour, 57, 315 - 324. doi:10.1006/anbe.1998.0957

Glantz, R. M. (1974). Defense reflex and motion detector responsiveness to approaching targets: The motion detector trigger to the defense reflex pathway. Journal of Comparative Physiology, 95, 297 - 314. doi:10.1007/BF00609703

Hazlett, B. A. (1985). Chemical detection of sex and condition in the crayfish Orconectes virilis. Journal of Chemical Ecology, 11, 181 - 189. doi:10.1007/BF00988201

Hollard, V. D., \& Delius, J. D. (1982). Rotational invariance in visual pattern recognition by pigeons and humans. Science, 218, 804 - 806. doi:10.1126/science.7134976

Homberg, U. (2008). Evolution of the central complex in the arthropod brain with respect to the visual system. Arthropod Structure and Development, 37, 347 - 362. doi:10.1016/j.asd.2008.01.008

How, M. J., Zeil, J., \& Hemmi, J. M. (2009). Variability of a dynamic visual signal: The fiddler crab claw-waving display. Journal of Comparative Physiology A: Neuroethology, Sensory, Neural, and Behavioral Physiology, 195, 55 - 67. doi:10.1007/s00359-008-0382-7

Ikeda, Y. (2009). A perspective on the study of cognition and sociality of cephalopod mollusks, a group of intelligent marine invertebrates. Japanese Psychological Research, 51, 146 - 153. doi:10.1111/j.14685884.2009.00401.x

Issa, F. A., Adamson, D. J., \& Edwards, D. H. (1999). Dominance hierarchy formation in juvenile crayfish Procambarus clarkii. The Journal of Experimental Biology, 202, 3497 - 3506.

Karavanich, C., \& Atema, J. (1998). Individual recognition and memory in lobster dominance. Animal Behaviour, 56, 1553 - 1560. doi:10.1006/anbe.1998.0914

Koch, L. M., Patullo, B. W., \& Macmillan, D. L. (2006). Exploring with damaged antennae: Do crayfish compensate for injuries? The Journal of Experimental Biology, 209, 3226 - 3233. doi:10.1242/jeb.02368

Langdon, J. W., \& Herrnkind, W. F. (1985). Visual shape discrimination in the fiddler crab, Uca pugilator. Marine Behaviour and Physiology, 11, 315 - 325. doi:10.1080/10236248509387056

Layne, J., Land, M., \& Zeil, J. (1997). Fiddler crabs use the visual horizon to distinguish predators from conspecifics: A review of the evidence. Journal of the Marine Biological Association of the United Kingdom, 77, 43 - 54. doi:10.1017/S0025315400033774

Mauck, B., \& Dehnhardt, G. (1997). Mental rotation in a California sea lion (Zalophus californianus). The Journal of Experimental Biology, 200, 1309 - 1316.

McMahon, A., Patullo, B. W., \& Macmillan, D. L. (2005). Exploration in a T-maze by the crayfish Cherax destructor suggests bilateral comparison of antennal tactile information. Biological Bulletin, $208,183-$ 188. doi: $10.2307 / 3593150$

Muller, K. J. (1973). Photoreceptors in the crayfish compound eye: Electrical interactions between cells as related to polarized-light sensitivity. The Journal of Physiology, 232, 573 - 595. DOI:10.1113/jphysiol.1973.sp010286

Nosaki, H. (1969). Electrophysiological study of color encoding in the compound eye of crayfish, Procambarus clarkii. Zeitschrift Für Vergleichende Physiologie, 64, 318 - 323. doi:10.1007/BF00340549

Oliva, D., Medan, V., \& Tomsic, D. (2007). Escape behavior and neuronal responses to looming stimuli in the crab Chasmagnathus granulatus (Decapoda: Grapsidae). The Journal of Experimental Biology, 210,865 - 80. doi:10.1242/jeb.02707

Page, T. L., \& Larimer, J. L. (1972). Entrainment of the circadian locomotor activity rhythm in crayfish. The role of the eyes and caudal photoreceptor. Journal of Comparative Physiology, 78, 107 - 120.

Regier, J. C., Shultz, J. W., \& Kambic, R. E. (2005). Pancrustacean phylogeny: Hexapods are terrestrial crustaceans and maxillopods are not monophyletic. Proceedings of the Royal Society B: Biological Sciences, 272, $395-$ 401. doi:10.1098/rspb.2004.2917

Sandeman, D. C. (1985). Crayfish antennae as tactile organs: Their mobility and the responses of their proprioceptors to displacement. Journal of Comparative Physiology A, 157, $363-373$. doi:10.1007/BF00618126

Sandeman, D. C. (1989). Physical properties, sensory receptors and tactile reflexes of the antenna of the Australian freshwater crayfish Cherax destructor. Journal of Experimental Biology, 141, 197 - 217.

Sandeman, D. C., \& Varju, D. (1988). A behavioural study of tactile localization in the crayfish Cherax destructor. Journal of Comparative Physiology - A Sensory, Neural, and Behavioral Physiology, 163, 525 - 536.

Schluessel, V., Kraniotakes, H., \& Bleckmann, H. (2014). Visual discrimination of rotated 3D objects in Malawi 
cichlids (Pseudotropheus sp.): A first indication for form constancy in fishes. Animal Cognition, 17, 359 371. doi:10.1007/s10071-013-0667-2

Schmidt, M. (2007). The olfactory pathway of decapod crustaceans - An invertebrate model for life-long neurogenesis. Chemical Senses, 32, 365 - 384. doi:10.1093/chemse/bjm008

Schmitz, B. (1992). Directionality of antennal sweeps elicited by water jet stimulation of the tailfan in the crayfish Procambarus clarkii. Journal of Comparative Physiology A, 171, 617 - 627. doi:10.1007/BF00194109

Sheehan, M. J., \& Tibbetts, E. A. (2011). Specialized face learning is associated with individual recognition in paper wasps. Science, 334, 1272 - 1275. doi:10.1126/science. 1211334

Smith, M. R., \& Dunham, D. W. (1990). Chela posture and vision: Compensation for sensory deficit in the crayfish Orconectes propinquus (Girard) (Decapoda, Cambaridae). Crustaceana, 59, 309 - 313.

Srinivasan, M. V. (2010). Honey bees as a model for vision, perception, and cognition. Annual Review of Entomology, 55, 267 - 284. doi:10.1146/annurev.ento.010908.164537

Tibbetts, E. A. (2002). Visual signals of individual identity in the wasp Polistes fuscatus. Proceedings of the Royal Society B: Biological Sciences, 269, 1423 - 1428. doi:10.1098/rspb.2002.2031

Vallortigara, G., Regolin, L., Chiandetti, C., \& Rugani, R. (2010). Rudiments of mind: Insights through the chick model on number and space cognition in animals. Comparative Cognition \& Behavior Reviews, 5, 78 - 99. doi:10.3819/ccbr.2010.50004

Van der Velden, J., Zheng, Y., Patullo, B. W., \& Macmillan, D. L. (2008). Crayfish recognize the faces of fight opponents. PLoS ONE, 3, e1695. doi:10.1371/journal.pone.0001695

van Hateren, J. H., Srinivasan, M. V., \& Wait, P. B. (1990). Pattern recognition in bees: Orientation discrimination. Journal of Comparative Physiology A, 167, 649 - 654. doi:10.1007/BF00192658

Zeil, J., Sandeman, R., \& Sandeman, D. (1985). Tactile localisation: The function of active antennal movements in the crayfish Cherax destructor. Journal of Comparative Physiology - A Sensory, Neural, and Behavioral Physiology, 157, $607-617$.

Zhang, S. W., Srinivasan, M. V., \& Collett, T. (1995). Convergent processing in honeybee vision: Multiple channels for the recognition of shape. Proceedings of the National Academy of Sciences of the United States of America, 92, 3029 - 3031. doi:10.1073/pnas.92.7.3029

Zulandt-Schneider, R. A., Schneider, R. W. S., \& Moore, P. A. (1999). Recognition of dominance status by chemoreception in the red swamp crayfish, Procambarus clarkii. Journal of Chemical Ecology, 25, 781 794. doi:10.1023/A:1020888532513 